\title{
Macrophage/Microglia Regulation of Astrocytic Tenascin: Synergistic Action of Transforming Growth Factor- $\beta$ and Basic Fibroblast Growth Factor
}

\author{
George M. Smith and Jason H. Hale \\ Department of Anesthesiology and Pain Management, University of Texas Southwestern Medical Center, \\ Dallas, Texas 75235-9068
}

\begin{abstract}
After injury to the CNS, extracellular matrix molecules such as tenascin are upregulated around the injury site and may be involved in inhibition of axon growth. In the present study, astrocytes were investigated to determine which cell types, growth factors, or cytokines are responsible for the injuryinduced regulation of tenascin. The addition of activated macrophage- or microglial-conditioned medium increased astrocytic expression of tenascin 2.5 -fold, as determined by Northern and Western blot analysis and ELISA. Of the cytokines and growth factors examined, only transforming growth factor- $\beta 1$ (TGF- $\beta 1$ ) and basic fibroblast growth factor (bFGF) significantly induced an increase in the production of astrocytic tenascin. Examination of macrophage and microglial supernatants showed the presence of TGF- $\beta 1$ but not bFGF; however, the TGF- $\beta 1$ concentration in supernatants was lower than that
\end{abstract}

expected to induce an increase in astrocytic tenascin similar to that seen with recombinant TGF- $\beta 1$. Western blot analysis of astrocytes showed only the presence of bFGF. Compared with the responses of the individual growth factors, tenascin production by astrocytes was dramatically potentiated when grown in the presence of a combination of both TGF- $\beta 1$ and bFGF. A similar synergistic effect was observed after the addition of either TGF- $\beta 1$ or bFGF to macrophage-conditioned medium. Northern analysis also showed concomitant increases in TGF- $\beta 1$, bFGF, and tenascin after CNS injury to animals $14 \mathrm{~d}$ of age or older. These results show that the regulation of astrocytic tenascin is mediated by the synergistic action of TGF- $\beta 1$ and bFGF in vitro and after injury in vivo.

Key words: microglia; extracellular matrix; astrocyte; growth factors; cytokines; glial-scar formation; wound healing
Extracellular matrix (ECM) molecules play an important role in mediating the wound-healing process in many tissues, including the CNS. In many regions of the adult CNS, ECM molecules, such as chondroitin sulfate proteoglycan (CSPG) and tenascin, are expressed at low levels; however, injury induces a prominent upregulation of their expression. This upregulation is primarily associated with reactive astrocytes that surround the injury site and secrete tenascin into the extracellular milieu (McKeon et al., 1991; Laywell et al., 1992). Immunohistological staining of tenascin shows that it is confined to the region surrounding the wound and within areas of degeneration in white matter tracts. This is particularly important with respect to tissue culture experiments that have demonstrated that tenascin can be inhibitory to neurite outgrowth and potentially refractory to axon regeneration through the wound site (Faissner and Kruse, 1990; Lochter et al., 1991; Gates et al., 1996).

The role tenascin and other extracellular matrix molecules play during CNS wound healing is unclear. Tenascin has been shown to have antiadhesive properties that may be involved in modulating cell migration or axonal growth (Lotz et al., 1989; Riou et al., 1990; Lochter et al., 1991). Tenascin also interacts with cell surface integrins (Sriramarao et al., 1993) as well as other ECM

Received July 16, 1997; revised Sept. 12, 1997; accepted Sept. 26, 1997.

This work was supported by National Institutes of Health Grant NS33776 and the Daniel Heumann Fund for Spinal Cord Research (G.M.S). We thank Scott Brady for critical review of this manuscript.

Correspondence should be addressed to Dr. George M. Smith, Department of Anesthesiology and Pain Management, University of Texas Southwestern Medical Center, 5323 Harry Hines Boulevard, Dallas, TX 75235-9068.

Copyright (C) 1997 Society for Neuroscience $0270-6474 / 97 / 179624-10 \$ 05.00 / 0$ molecules, such as proteoglycans, several forms of collagen (Faissner et al., 1990), and fibronectin (Chiquet-Ehrismann et al., 1991). This indicates that tenascin is most likely involved in matrix organization as well as in cell-substrate interactions (Lightner and Erickson, 1990) and may contribute to the formation of glial scarring.

Injury to the adult CNS produces a complex series of cellular interactions that ultimately results in the establishment of gliosis, or glial scar formation. Two prominent cell types involved in mediating the wound-healing response are microglia/macrophages and astrocytes. Shortly after injury, hematopoietic macrophages and microglia become activated and release a myriad of cytokines and growth factors. Cytokines, such as interleukin-1 (IL-1) and interferon- $\gamma($ IFN- $\gamma)$, have been shown to induce astrocyte proliferation and hypertrophy, thus, potentially producing reactive gliosis (Giulian et al., 1988; Yong et al., 1991). Other factors believed to be released by macrophages and microglia are transforming growth factor- $\beta 1$ (TGF- $\beta 1$ ) and basic fibroblast growth factor (bFGF). In several studies, TGF- $\beta 1$ has been shown to stimulate fibroblasts to increase their production and secretion of several extracellular molecules, including fibronectin and tenascin (Pearson et al., 1988). Increased expression of fibronectin and laminin was observed in astrocytes treated with TGF- $\beta 1$ (Baghdassarian et al., 1993) as well as in brains of transgenic mice overexpressing TGF- $\beta 1$ (Wyss-Coray et al., 1995). Tenascin expression also was observed to increase in astrocytes stimulated by bFGF (Meiners et al., 1993). These studies indicate that injury-induced factors or cytokines secreted by activated macrophages and microglia have the potential of upregulating the expression of ECM molecules. A thorough examination of tenascin regulation by astrocytes grown 
in the presence of cytokines, growth factors, or activated macrophage- and microglial-conditioned media has never been done.

The present study examines the regulation of tenascin by astrocytes grown in activated macrophage- or microglialconditioned medium or in the presence of specific growth factors or cytokines known to be upregulated after CNS injury. Activated macrophage- or microglial-conditioned medium induces a dose-dependent increase in tenascin production and secretion by astrocytes. This upregulation of tenascin by astrocytes is induced by an apparent synergistic effect between TGF- $\beta 1$ released from macrophages and microglia and bFGF expressed by astrocytes. Northern blot analysis of normal and injured brain correlates well with these in vitro observations, demonstrating concomitant increases in tenascin, TGF- $\beta 1$, and bFGF after injury. Identification of the factors that regulate tenascin expression after injury will allow manipulation of tenascin expression and evaluation of its role in CNS wound healing and axonal regeneration.

\section{MATERIALS AND METHODS}

Cell cultures. Purified astrocytes were prepared from newborn rat cerebral cortices using a modification of the method of Smith et al. (1990). Cerebral cortices were isolated, and meningeal tissue was removed and incubated in calcium and magnesium-free buffer (MEM-CMF) containing $0.025 \%$ trypsin and $2 \mathrm{~mm}$ EDTA for $30 \mathrm{~min}$ at $37^{\circ} \mathrm{C}$. Digestion was terminated with the addition of an equal volume of DMEM (GIBCO/ BRL) containing $10 \%$ fetal bovine serum (FBS) and $100 \mu \mathrm{l}$ of a solution of $0.5 \mathrm{mg} / \mathrm{ml}$ DNase. Cells were dissociated by trituration through a fire-polished Pasteur pipette, plated into polylysine-coated $(0.1 \mathrm{mg} / \mathrm{ml})$ $75 \mathrm{~cm}^{2}$ tissue culture flasks at a density of $2.0 \times 10^{7}$ cells/flask, and incubated at $37^{\circ} \mathrm{C}$ with $5 \% \mathrm{CO}_{2}$ overnight. Nonadherent cells were removed by shaking, and the medium was replaced. Once cells reached confluence (5-7 d), microglia were extracted using the procedure of Giulian and Baker (1986). Extracted microglia were plated into $60 \mathrm{~mm}$ dishes at a density of $1 \times 10^{6}$ cells/dish. Astrocytes were purified further by more vigorous shaking and treatment of cultures for $2 \mathrm{~d}$ with $1 \times 10^{-5}$ M cytosine arabinoside. After 3-4 weeks, astrocytes were plated onto 24-well plates (150,000 cells/well) and grown in Sato's N2 medium for at least $48 \mathrm{hr}$ before addition of cytokines or conditioned medium. All cytokines or conditioned medium were diluted to $0.5 \mathrm{ml}$ in Sato's N2 medium before addition to the wells. In all experiments, astrocytes were grown for an additional $48 \mathrm{hr}$ after the addition of the cytokines or conditioned medium. All experiments also included Sato's N2 medium and activated macrophage-conditioned medium (-CM) controls.

Macrophages were isolated by injecting $20 \mathrm{ml}$ of MEM-CMF into the peritoneal cavity of anesthetized rats. After several minutes, the cavity was opened under a sterile dissection hood, and the medium was removed using a Pasteur pipette. Macrophages from two to three animals were collected, pooled, placed on ice for $10 \mathrm{~min}$, and centrifuged at 1000 $\mathrm{rpm}$ for $10 \mathrm{~min}$. Cells were resuspended in $10 \mathrm{ml}$ of DMEM containing $10 \%$ FBS and plated onto a $100 \mathrm{~mm}$ dish. After $4 \mathrm{hr}$, the nonadherent cells were removed and discarded. The adherent macrophages were extracted from the dish using a $0.025 \%$ trypsin solution containing $2 \mathrm{~mm}$ EDTA and replated at $1 \times 10^{6}$ cells per $60 \mathrm{~mm}$ dish.

Zymosan-A-activated macrophage-conditioned medium. Peritoneal macrophages and brain microglia were isolated and plated in DMEM containing $10 \% \mathrm{FBS}$ for $48 \mathrm{hr}$ at $37^{\circ} \mathrm{C}$ in $5 \% \mathrm{CO}_{2}$. Macrophages were washed twice in serum-free Sato's N2 medium to remove serum residue and were incubated for $48 \mathrm{hr}$ in Sato's N2 medium containing $100 \mu \mathrm{g} / \mathrm{ml}$ zymosan-A (Sigma, St. Louis, MO). Preboiled zymosan-A stimulates peritoneal macrophages and microglia to secrete cytokines (Sanguedolce et al., 1992). After a $48 \mathrm{hr}$ incubation at $37^{\circ} \mathrm{C}$ in $5 \% \mathrm{CO}_{2}$, activated macrophage-conditioned medium was isolated, centrifuged at $5000 \times g$ for $15 \mathrm{~min}$, filtered through a $0.2 \mu \mathrm{m}$ filter (Millipore, Bedford, MA), and stored at $-80^{\circ} \mathrm{C}$. Zymosan-A consists of particles of killed yeast that are effectively removed from supernatants by centifugation and filtration to avoid contaminating astrocyte cultures.

Western blot analysis. Identical amounts $(500 \mu \mathrm{l})$ of astrocyte supernatant, after various treatments, were precipitated in 10 volumes of acetone at $-20^{\circ} \mathrm{C}$ for $2 \mathrm{hr}$ to overnight. Proteins were pelleted by centrifugation at $15,000 \mathrm{rpm}$, dried, and resuspended in $100 \mu \mathrm{l}$ of Laemmli's buffer. To each well of a $6 \%$ SDS-polyacrylamide gel was added $40 \mu$ of sample. After running the gel, proteins were transferred to a polyvinylidene difluoride membrane. Membranes were blocked using 5\% nonfat dry milk in Tris-buffered saline with $0.05 \%$ Tween-20 (TBST). Proteins of interest were identified using rabbit anti-tenascin (1:500; GIBCO/BRL), chicken anti-TGF- $\beta 1$ (1:500; R \& D Systems, Minneapolis, MN), or goat anti-bFGF (1:500; R \& D Systems) in blocking solution. After a $3 \mathrm{hr}$ incubation in primary antibody, the membranes were washed five times for $10 \mathrm{~min}$ each in TBST. After washing, the membranes were incubated in either goat anti-rabbit IgG (1:7500; Promega, Madison, WI), goat anti-chicken IgG (1:5000; Jackson ImmunoResearch, West Grove, PA), or donkey anti-goat (1:5000; Jackson ImmunoResearch) conjugated with alkaline phosphatase for $2 \mathrm{hr}$. Membranes were washed as above and developed using 5-bromo-4-chloro-3-indolyl phosphate/nitroblue tetrazolium solutions (Boehringer Mannheim, Indianapolis, IN).

ELISA. For these experiments ELISAs were done similar to the procedure of Lightner and Erickson (1990). For each experiment, $50 \mu \mathrm{l}$ of medium was transferred to ELISA plates, and proteins were bound overnight. Nonspecific background was blocked by adding $200 \mu \mathrm{l}$ of TBST containing $2 \%$ powdered milk (Blotto) for $2 \mathrm{hr}$ at room temperature. To five of the six wells (the sixth well is a secondary antibody control and blank) anti-tenascin (1:800) diluted in Blotto was added and incubated for $3 \mathrm{hr}$. Wells were washed six times in TBST and incubated in alkaline phosphatase-conjugated antibody (1:3000 in Blotto; Promega) for $2 \mathrm{hr}$. The wells were washed as above, developed with $0.5 \mathrm{mg} / \mathrm{ml}$ $p$-nitrophenyl phosphate (Sigma) dissolved in buffer $\left(0.1 \mathrm{M} \mathrm{Na}_{2} \mathrm{CO}_{3}\right.$ and $5 \mathrm{mM} \mathrm{MgCl}_{2}$ at $\mathrm{pH} 9.5$ ), and recorded at $405 \mathrm{~nm}$ in a microplate reader (EL-311; Bio-Tek Instruments, Burlingame, CA).

For quantifying the amount of TGF- $\beta 1$ in activated macrophageconditioned medium, a two-site ELISA system was used as described by Danielpour et al. (1990). To capture TGF- $\beta 1$ from conditioned medium, we added $50 \mu \mathrm{l}$ of a PBS solution containing $20 \mu \mathrm{g} / \mathrm{ml}$ monoclonal anti-TGF- $\beta 1$ (Genzyme, Boston, MA) to a 96 well plate. After a $2 \mathrm{hr}$ incubation at room temperature, the wells were washed three times with TBS and blocked as described above. Fifty microliters of either activated macrophage-, microglial-, or astrocyte-CM were added to six wells and incubated as above. In addition, a titration curve of purified TGF- $\beta 1(0$, $0.05,0.1,0.25,0.5,0.75,1.0$, and $2.0 \mathrm{ng} / 50 \mu \mathrm{l}$ ) in Sato's N2 medium was done in triplicate. The rest of the procedure is as described above except that the detection antibody used was chicken anti-TGF- $\beta 1$ (1:1000) followed by goat anti-chicken (1:2500) alkaline phosphatase-conjugated secondary antibody.

Brain lesions and RNA isolation. Newborn and adult rats were lesioned by inserting a microknife through the cortex to sever the corpus callosum lateral to the ventricle [similar to the procedure of Lindsay et al. (1982)]. To create the lesions, we cut and retracted the skin on adult rats. A small groove was cut through the skull $\sim 2.5 \mathrm{~mm}$ from the midsagittal sinus extending $\sim 6-7 \mathrm{~mm}$ between the landmarks lambda and bregma. A microknife was inserted through the groove $5 \mathrm{~mm}$ into the cortex and moved along the groove, cutting through the body of the corpus callosum. For rat pups, the microknife was inserted $2 \mathrm{~mm}$ anterior to bregma and $1 \mathrm{~mm}$ lateral to the midsagittal sinus and slowly brought up through the corpus callosum. All animals were killed $3 \mathrm{~d}$ after injury.

Northern blot analysis of RNA samples. Total RNA was isolated from age-matched normal and lesioned rat brains using the guanidinium thiocyanate-phenol-chloroform (Xie and Rothblum, 1991) method. RNA quality was determined by agarose gel electrophoresis and from its absorbance at 260 and $280 \mathrm{~nm}$. Identical amounts of total RNA isolated from normal and lesioned rat brains of various ages were electrophoresed on a $1 \%$ agarose gel containing $0.66 \mathrm{M}$ formaldehyde and $1 \times$ gel-running buffer (40 mm morpholinopropanesulfonic acid, MOPS, pH 7.0; $10 \mathrm{~mm}$ sodium acetate; and 1 mM EDTA). The RNA was transferred to a Nytran membrane (Schleicher \& Schuell, Keene, NH) and cross-linked by UV irradiation in a Stratolinker (Stratagene, La Jolla, CA). Nonspecific hybridization was blocked by incubating the membrane in prehybridization solution $[10 \times$ Denhardt's solution, $50 \%$ formamide, $5 \times$ salinesodium phosphate-EDTA buffer (SSPE), $0.2 \mathrm{mg} / \mathrm{ml}$ sheared-salmon sperm DNA, $100 \mu \mathrm{g} / \mathrm{ml}$ yeast tRNA, and $0.5 \%$ SDS] overnight at $60^{\circ} \mathrm{C}$. After prehybridization, Northern blots were incubated overnight with ${ }^{32} \mathrm{P}$-labeled probe $\left(1 \times 10^{6} \mathrm{cpm} / \mathrm{ml}\right)$ under the same conditions as described for prehybridization and were washed in $1 \times$ SSPE and $0.5 \%$ SDS three times at $65^{\circ} \mathrm{C}$ with a final wash in $0.1 \times$ SSPE and $0.5 \%$ SDS at $65-70^{\circ} \mathrm{C}$. RNA bands were identified by autoradiography.

To generate cRNA probes, we incubated linearized vector $(0.2-1.0 \mu \mathrm{g})$ in $1 \times$ transcription buffer $\left(40 \mathrm{~mm}\right.$ Tris, $\mathrm{pH} 7.5,6 \mathrm{~mm} \mathrm{MgCl}_{2}, 2 \mathrm{~mm}$ 


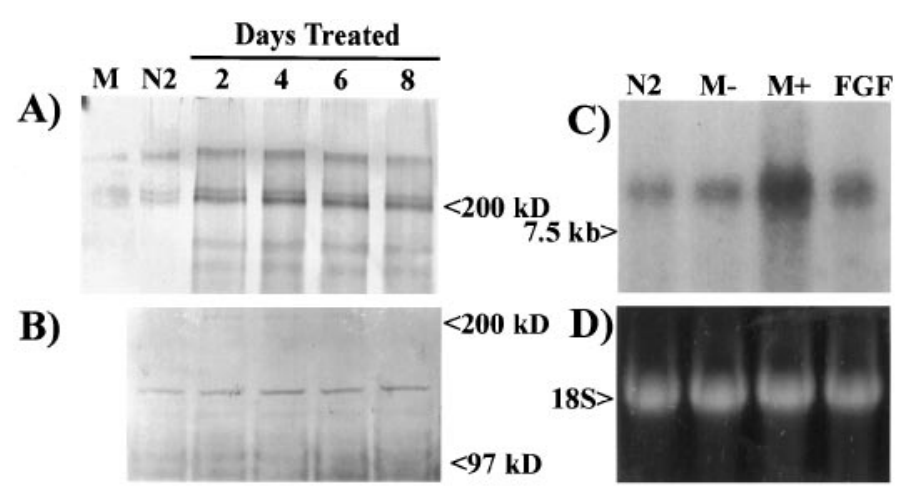

Figure 1. Tenascin expression by astrocytes increases after treatment with zymosan-activated macrophage-conditioned medium. $A$, Western blot analysis of culture supernatants from astrocytes treated with $50 \%$ activated macrophage-conditioned medium shows an increase in tenascin (200 and $250 \mathrm{kDa}$ ) release compared with activated macrophage-CM $(M)$ alone or astrocytes treated for $2 \mathrm{~d}$ in Sato's N2 medium (N2). B, Examination of astrocyte monolayers shows no change in the level of tenascin expression on the surface of astrocytes. $C$, Northern blot analysis of total mRNA (10 $\mu \mathrm{g} /$ lane) isolated from astrocytes shows a large increase in tenascin mRNA $(8.0 \mathrm{~kb})$ expression after a $48 \mathrm{hr}$ treatment with activated macrophage-CM $(M+)$ and a minor increase after treatment with nonactivated macrophage-CM $(M-)$ or basic fibroblast growth factor $(F G F)$. $D$, Ethidium bromide-labeled $18 \mathrm{~S}$ ribosomal RNA from the same Northern blot demonstrates equal loading of RNA.

spermidine, and $10 \mathrm{~mm} \mathrm{NaCl}$ ), $10 \mathrm{~mm}$ DTT, $1 \mathrm{U} / \mu \mathrm{l} \mathrm{RNasin}$ (Promega), $0.5 \mathrm{~mm}$ NTPs (ATP, GTP, and UTP), $12 \mu \mathrm{M} \mathrm{CTP}, 25 \mu \mathrm{Ci}\left[\alpha^{32} \mathrm{P}\right] \mathrm{CTP}$, and $5 \mathrm{U}$ of $\mathrm{T} 3$ polymerase (Promega) for $60 \mathrm{~min}$ at $37^{\circ} \mathrm{C}$. DNA templates were removed by adding $1 \mathrm{U}$ of RNase-free DNase I (Boehringer Mannheim) and incubating at $37^{\circ} \mathrm{C}$ for $15 \mathrm{~min}$. Proteins were removed by phenol/chloroform extraction, and free nucleosides were removed over a G-50 Sepharose (Pharmacia, Piscataway, NJ) column. Radioactivity of the probe was then determined using a Beckman scintillation counter. cRNA probe was generated from tenascin cDNA vector pTFN (gift from Dr. U. Dorries), TGF- $\beta 1$ cDNA vector pRTGF $\beta 1$ (Recombinant DNA; American Type Culture Collection, Rockville, MD), and bFGF cDNA vector pRObFGF503 (gift from Dr. A. Baird, Prizm Pharmaceut, San Diego, CA).

\section{RESULTS}

\section{Activated macrophage- and microglial-conditioned media induce astrocytes to increase their production and secretion of tenascin}

After traumatic injury to the CNS that disrupts the vasculature, both hematopoietic monocytes and microglia infiltrate the wound, become activated, and secrete numerous cytokines and growth factors that can influence astrocyte proliferation and expression of surface proteins. Thus, these cells are very important in mediating the wound-healing process. For these reasons, both hematopoietic monocytes (isolated from the peritoneal cavity) and microglia were tested to determine whether they could induce an increase in the production of astrocytic tenascin. Higher amounts of tenascin were released in the supernatants of astrocytes treated for 2, 4, 6, and $8 \mathrm{~d}$ with $50 \%$ activated macrophage-CM compared with chemically defined medium alone or activated macrophage-CM alone (Fig. $1 A$ ). Each time point reflects the complete removal of 2-d-old conditioned medium and the replacement with fresh 50\% macrophage-CM. Analysis of the astrocyte monolayers indicated no increase in tenascin associated with the cell surface (Fig. $1 B$ ). To determine whether the increase in tenascin observed in the astrocyte supernatant was caused by an increase in release of protein or synthesis, we examined total RNA from astrocytes grown for $48 \mathrm{hr}$ in
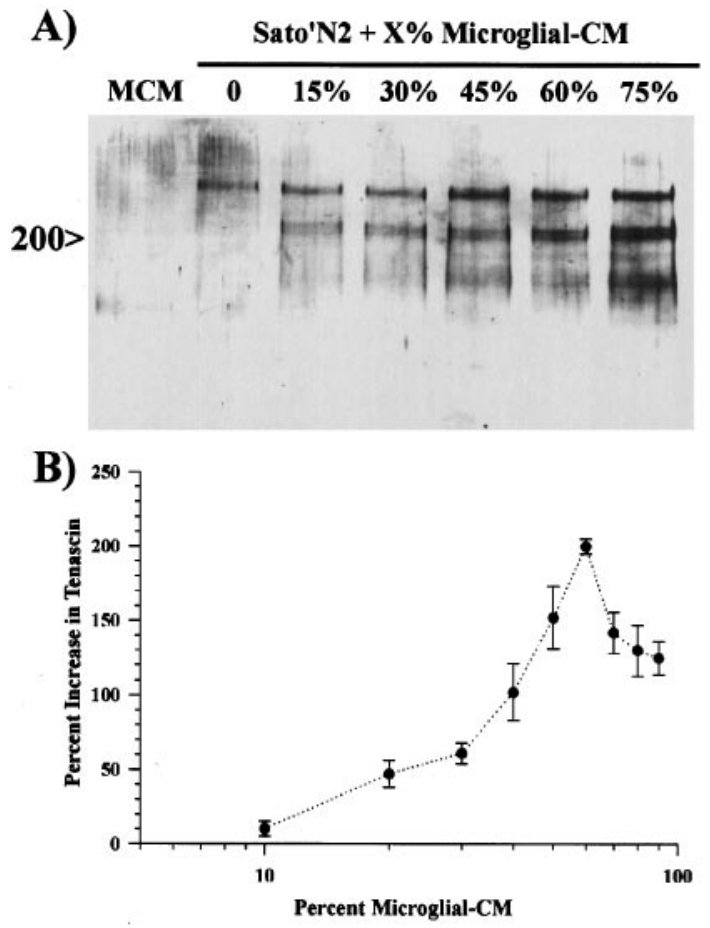

Figure 2. Zymosan-activated microglial-conditioned medium induces a dose-dependent increase in tenascin production by astrocytes. $A$, Western blot analysis of culture supernatants from astrocytes grown in $0,15,30,45$, 60 , or $75 \%$ activated microglial-conditioned media shows a dosedependent increase in tenascin production by astrocytes. Activated microglial-conditioned medium (MCM) did not contain detectable amounts of tenascin. $B$, To quantify tenascin secretion, we grew astrocyte monolayers for $48 \mathrm{hr}$ in Sato's N2 medium alone or in differing amounts of activated microglial-CM. Tenascin content in the supernatants was determined by ELISA and normalized to tenascin expression by astrocytes grown in Sato's N2 medium. Quantitative analysis by ELISA revealed a $\mathrm{ED}_{50}$ of $\sim 40 \%$ and a maximal dose of $60 \%$ activated macrophage-CM. Error bars represent the SD.

Sato's N2 medium, 50\% nonactivated macrophage-CM, 50\% activated macrophage-CM, and $10 \mathrm{ng} / \mathrm{ml}$ bFGF by Northern blot analysis (Fig. 1C,D). Astrocytes grown in the presence of activated macrophage-CM for $48 \mathrm{hr}$ showed an increase in tenascin mRNA. A slight increase in tenascin mRNA was also observed after treatment with $10 \mathrm{ng} / \mathrm{ml} \mathrm{bFGF}$. These data show that factors present in activated macrophage-CM induce the transcriptional upregulation of tenascin.

To determine whether activated microglial-CM also increases the production of tenascin by astrocytes and whether this increase was dependent on the relative concentration of activated microglial-CM, we treated astrocyte monolayers for $48 \mathrm{hr}$ with different concentrations of activated microglial-CM. Western blot analysis showed a dose-dependent increase in the amounts of tenascin within astrocyte supernatants (Fig. 2A). In all Western blots, the addition of either activated macrophage-CM or activated microglial-CM induced the expression of three tenascin isoforms, a single band at $250 \mathrm{kDa}$ and a doublet at $200 \mathrm{kDa}$. The $200 \mathrm{kDa}$ doublet was usually less abundant when astrocytes were grown in serum-free conditions, and no tenascin was observed in activated microglial-CM (Fig. $2 A$ ). Similar dose-dependent increases were also observed with the addition of activated macrophage-CM to astrocytes (data not shown). Quantitative analysis by ELISA indicated that the concentrations of tenascin began increasing above $10 \%$ added activated microglial-CM and 

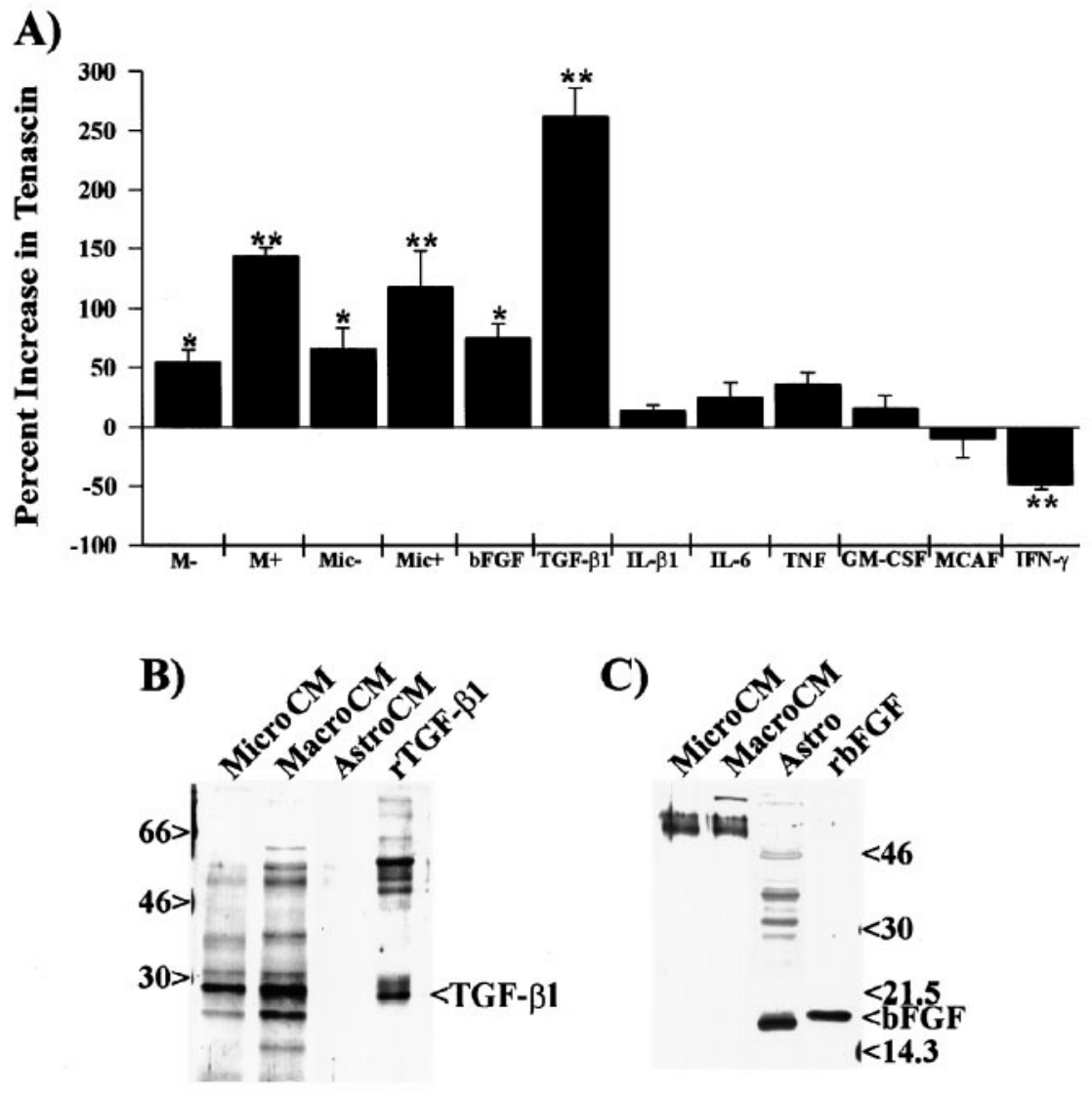

Figure 3. In addition to macrophage- and microglialconditioned medium, only TGF- $\beta 1$ and bFGF caused increased production of tenascin by astrocytes. $A$, The amount of tenascin secreted by astrocytes grown in the presence of activated macrophage-conditioned medium or specific cytokines was examined by ELISA. For these experiments, astrocytes were plated into the wells of a 96 well plate $(20,000$ cells per well) and grown in the presence of Sato's N2 medium, $50 \%$ nonactivated macrophage-CM $(M-)$, $50 \%$ zymosan-activated macrophage-CM $(M+)$, $50 \%$ nonactivated microglial-CM (Mic-), $50 \%$ zymosan-activated microglial-CM $(M i c+), 10 \mathrm{ng} / \mathrm{ml}$ bFGF, $10 \mathrm{ng} / \mathrm{ml}$ TGF- $\beta 1,10 \mathrm{ng} / \mathrm{ml}$ IL- $\beta 1,25 \mathrm{U} / \mathrm{ml}$ IL-6, $2500 \mathrm{U} / \mathrm{ml}$ TNF- $\alpha, 50 \mathrm{U} / \mathrm{ml}$ GM-CSF, $10 \mathrm{ng} / \mathrm{ml}$ $\mathrm{MCAF}$, or $200 \mathrm{U} / \mathrm{ml} \mathrm{IFN-} \gamma$ for $48 \mathrm{hr}$. All data points were normalized to the tenascin expression from astrocytes grown in Sato's N2 medium. Other cytokines and growth factors (CNTF, LIF, PDGF-AB, EGF, and IGF I and II) were also tested and showed no statistically significant increase in tenascin production by astrocytes. Error bars represent the SD $* p<0.01 ; * p<0.001$. B, Western blot analysis of 48 hr-conditioned media from activated microglia (MicroCM), activated macrophages (MacroCM), and astrocytes $($ AstroCM $)$ revealed that microglia and macrophages, but not astrocytes, release detectable amounts of TGF- $\beta 1$ into their respective media. $C$, Western blot analysis of activated microglial-CM, activated macrophage-CM, and astrocyte monolayers (Astro) shows that only astrocytes contained detectable amounts of bFGF. As positive controls, each blot contains either recombinant human TGF- $\beta 1$ $(r T G F-\beta 1)$ or recombinant human bFGF $(r b F G F)$. peaked at a concentration of $\sim 60 \%$ (Fig. $2 B$ ). At higher concentrations, there was actually a decrease in the amount of observable tenascin within the astrocyte supernatants. This was most likely because of the fact that at these higher concentrations the medium would acidify between 24 and $48 \mathrm{hr}$ of treatment. In addition, we also observed some cell death for treatments longer than $24 \mathrm{hr}$, and the monolayers often retracted and detached from the dish within $48 \mathrm{hr}$. Many of these cells were still viable and could be dissociated and replated onto a fresh dish; however, they would not reattach to the original dish. These data show a dose-dependent relationship between the concentration of activated microglial-CM and astrocyte production of tenascin.

\section{Transforming growth factor- $\beta 1$ and basic fibroblast growth factor stimulate tenascin production and act synergistically}

To examine which of these factors could potentially affect the production of tenascin, we examined astrocyte-conditioned medium $48 \mathrm{hr}$ after treatment with various factors (Fig. 3). Quantitative analysis by ELISA shows that $50 \%$ activated microglial$\mathrm{CM}, 50 \%$ activated macrophage-CM, $10 \mathrm{ng} / \mathrm{ml}$ TGF- $\beta 1$, and 10 $\mathrm{ng} / \mathrm{ml} \mathrm{bFGF}$ increased tenascin production by $118,143,262$, and $80 \%$, respectively, when compared with tenascin released by astrocytes grown in Sato's N2 medium alone (Fig. $3 A$ ). We also observed a consistent decrease $(\sim 50 \%)$ in tenascin production when astrocytes were grown in the presence of $200 \mathrm{U} / \mathrm{ml}$ IFN- $\gamma$. In addition to these factors, no statistically significant change in tenascin was observed after a $48 \mathrm{hr}$ treatment of astrocytes with interleukin- $\beta 1$ (IL- $\beta 1$ ), interleukin-6 (IL-6), tumor necrosis factor (TNF- $\alpha$ ), granulocyte-macrophage colony-stimulating factor (GM-CSF), macrophage chemoattractant and activating factor
(MCAF), ciliary neurotrophic factor (CNTF), leukemia inhibitory factor (LIF), platelet-derived growth factor (PDGF-AB), epidermal growth factor (EGF), insulin-like growth factor I (IGF I), IGF II, or zymosan-A. These factors were examined because they are known to be expressed after brain injury by either macrophages (IL- $\beta 1$, IL- 6 , TNF- $\alpha$, EGF, and bFGF), astrocytes (GM-CSF, MCAF, CNTF, bFGF, and IGF), T cells (IFN- $\gamma$ ), or platelets (PDGF) and function in either the activation of macrophages and microglia, cell proliferation, or reactive gliosis (for review, see Lotan and Schwartz, 1994; Gehrmann et al., 1995). These data show that of all the cytokines and growth factors examined, only TGF- $\beta 1$ and bFGF induce an increase in tenascin production by astrocytes, with TGF- $\beta 1$ having a more robust effect.

Although many of these growth factors influence astrocyte proliferation, there seemed to be no correlation between the extent of proliferation and tenascin production. To determine cell proliferation, astrocytes were treated for $48 \mathrm{hr}$ in the presence or absence of growth factors, fixed with $\mathrm{MeOH}$ at $-20^{\circ} \mathrm{C}$, and stained with ethidium bromide, and the number of nuclei were counted from 10 randomly selected fields or samples using MetaMorph image analysis software. These data show no statistically significant difference in the number of nuclei when astrocytes were grown in TGF- $\beta 1$ and only a slight increase when grown in bFGF $(18 \pm 1.9 \%)$, IFN- $\gamma(17 \pm 2.5 \%)$, or a combination of bFGF and TGF- $\beta 1(18 \pm 1.7 \%)$ when compared with astrocytes grown in the absence of these factors. We did observe, however, a dramatic increase in cell proliferation after the addition of either PDGF or EGF (56 $\pm 13 \%$ and $43 \pm 25 \%$, respectively). Even though cell division rates increased by almost $50 \%$ after the 
addition of PDGF or EGF, no increase was observed in tenascin expression in these supernatants.

Both TGF- $\beta 1$ and bFGF are known to be expressed after brain injury in microglia and astrocytes. To determine whether these factors are present in our activated microglial-, activated macrophage-, or astrocyte-conditioned media, we examined each conditioned medium by Western blot analysis. Western blots of nonreduced proteins precipitated from $1.0 \mathrm{ml}$ of conditioned medium showed the presence of TGF- $\beta 1$ protein in both activated microglial-CM and activated macrophage-CM but not in astrocyte-conditioned medium (Fig. $3 B$ ). Under these nonreducing conditions, the active form of the TGF- $\beta 1$ dimer can be observed migrating at $25 \mathrm{kDa}$. Protein bands that migrated at 40 and $31 \mathrm{kDa}$ most likely represent the inactive preprocessed forms of TGF- $\beta 1$. Quantitative analysis by ELISA of the amount of TGF- $\beta 1$ in these media indicate a relative concentration of $4.1 \pm$ $0.8 \mathrm{ng} / \mathrm{ml}$ or $5.3 \pm 0.4 \mathrm{ng} / \mathrm{ml}$ for media isolated from $1 \times 10^{6}$ activated microglia or macrophages, respectively. No detectable amount of bFGF was observed on identical Western blots of conditioned media. Solubilization and examination of cytosolic proteins by Western blot analysis show detectable amounts of bFGF in astrocytes but not in activated microglial- or macrophage-CM (Fig. $3 C$ ). These results indicate that TGF- $\beta 1$ but not bFGF is released from activated macrophages and microglia.

The concentration of TGF- $\beta 1$ detected in our activated microglial- or macrophage-conditioned media is less than half of what would be predicted for an equivalent increase in tenascin by purified TGF- $\beta 1$. Although bFGF is not detected in activated microglial-, macrophage-, or normal astrocyteconditioned media, bFGF has been hypothesized to be released by cell death or perturbation (McNeil et al., 1989). To determine whether bFGF release could potentiate tenascin production in the presence of TGF- $\beta 1$, we examined the dosedependent expression of astrocytic tenascin in the presence of TGF- $\beta 1$, bFGF, and a mixture of both TGF- $\beta 1$ and bFGF at equal concentrations. Western blot analysis of supernatants from astrocytes treated for $48 \mathrm{hr}$ in $0.5,1.0,5.0,10.0,20.0$, and $40.0 \mathrm{ng} / \mathrm{ml}$ TGF- $\beta 1$ shows a dose-dependent increase in tenascin production (Fig. $4 A$ ). Tenascin production from astrocytes treated with $50 \%$ activated macrophage-CM seemed similar to that between 5 to $10 \mathrm{ng} / \mathrm{ml}$ TGF- $\beta 1$. Western blot analysis of astrocyte supernatants treated with a combination of both TGF- $\beta 1$ and bFGF also showed a dose-dependent increase in tenascin production but at much lower concentrations of TGF- $\beta 1$ (Fig. $4 B$ ). These growth factors also seemed to regulate the expression of tenascin isoforms differentially. In the presence of TGF- $\beta 1$, there is a more prominent increase in the doublet at $200 \mathrm{kDa}$ than in the $250 \mathrm{kDa}$ band; however, bFGF seems to have the opposite effect. An identical difference in the regulation of tenascin isoforms by either TGF- $\beta 1$ or bFGF has also been observed in fibroblasts (Tucker et al., 1993). Quantitative analysis of tenascin by ELISA shows a dramatic difference between the effects of TGF- $\beta 1$ alone and in combination with bFGF (Fig. $4 C$ ). The combination of TGF- $\beta 1$ and bFGF showed a maximal increase in tenascin of $700 \%$ at $5.0 \mathrm{ng} / \mathrm{ml}$ and an $\mathrm{ED}_{50}$ of $350 \%$ between 1.5 and $2.0 \mathrm{ng} / \mathrm{ml}$, whereas for TGF- $\beta 1$ alone, the maximal increase was $400 \%$ at $\sim 20 \mathrm{ng} / \mathrm{ml}$, and the $\mathrm{ED}_{50}$ was $\sim 200 \%$ between 6 and $7 \mathrm{ng} / \mathrm{ml}$. These data show that the addition of an equal amount of bFGF to TGF- $\beta 1$ increases the maximal amount of tenascin almost twofold at less than one-third the concentration of TGF- $\beta 1$ needed alone.

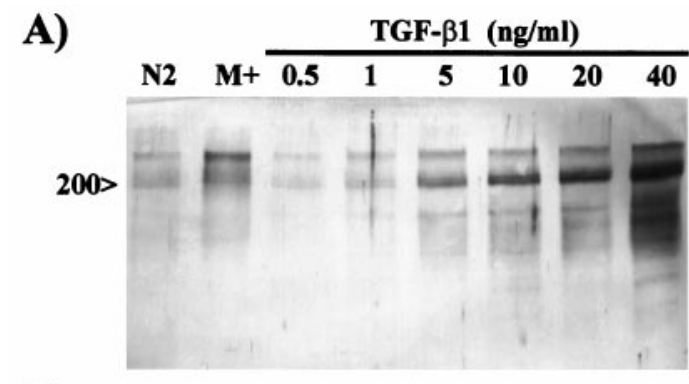

B)

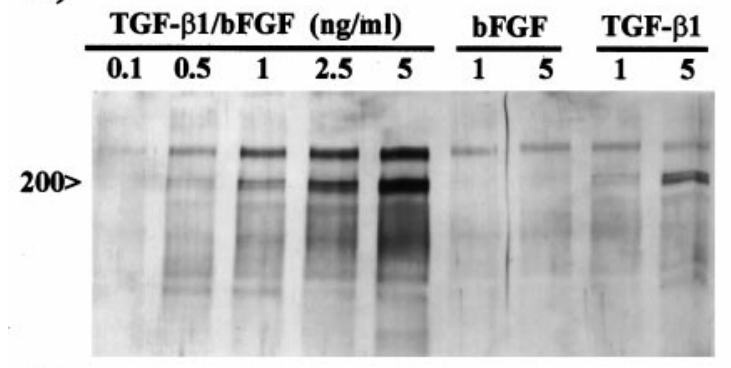

C)

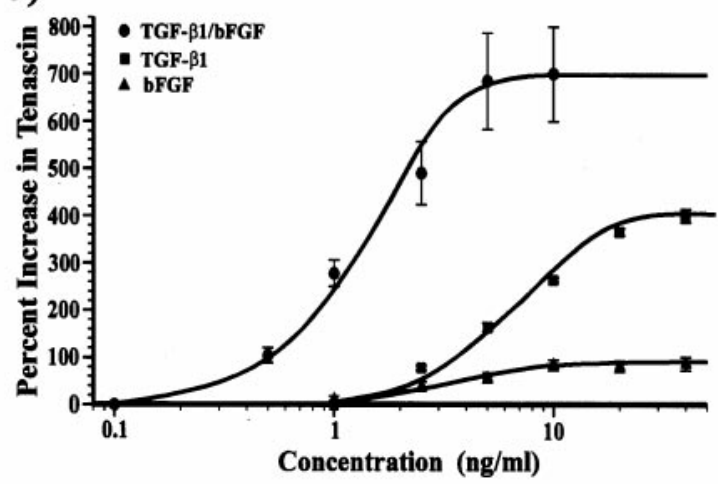

Figure 4. Astrocyte production of tenascin in the presence of TGF- $\beta 1$ is potentiated by bFGF. Astrocyte monolayers were grown in the presence of Sato's N2 medium alone (N2) or in 50\% activated macrophage-CM $(M+)$, TGF- $\beta 1$, bFGF, or a combination of TGF- $\beta 1$ and bFGF for $48 \mathrm{hr}$. Western blot analysis of supernatants shows that TGF- $\beta 1(A)$ and TGF- $\beta 1$ and bFGF $(B)$ cause a dose-dependent increase in tenascin production by astrocytes. $C$, Quantitation and comparison of the relative amounts of tenascin in the supernatants show that bFGF potentiates the effect of TGF- $\beta 1$ by approximately twofold, increasing the $\mathrm{ED}_{50}$ at lower concentrations of TGF- $\beta 1$. Error bars represent the SD. The concentrations of TGF- $\beta 1$ and bFGF combinations represent the amount of each factor.

\section{Macrophage and microglial induction of tenascin is dependent on synergistic activity between TGF- $\beta 1$ and bFGF}

To examine the possibility that tenascin expression by astrocytes grown in the presence of activated microglial- or macrophage-CM is caused by the synergistic action of TGF- $\beta 1$ and bFGF, we grew astrocytes for $48 \mathrm{hr}$ in $50 \%$ activated macrophage-CM in the presence of $2.5 \mathrm{ng} / \mathrm{ml}$ TGF- $\beta 1$ or bFGF (Fig. $5 A$ ). The addition of either bFGF or TGF- $\beta 1$ to macrophage-CM induced an increase in tenascin production, which was on average 2.5 -fold higher than that of $40 \%$ activated macrophage-CM alone, 5.75-fold higher than that of $5 \mathrm{ng} / \mathrm{ml} \mathrm{bFGF}$, and 2.15-fold higher than that of $5 \mathrm{ng} / \mathrm{ml}$ TGF- $\beta 1$. This increase was also slightly higher than that of a combination of $2.5 \mathrm{ng} / \mathrm{ml} \mathrm{TGF}-\beta 1$ and bFGF. These data show that the addition of either bFGF or TGF- $\beta 1$ to macrophage-CM can 

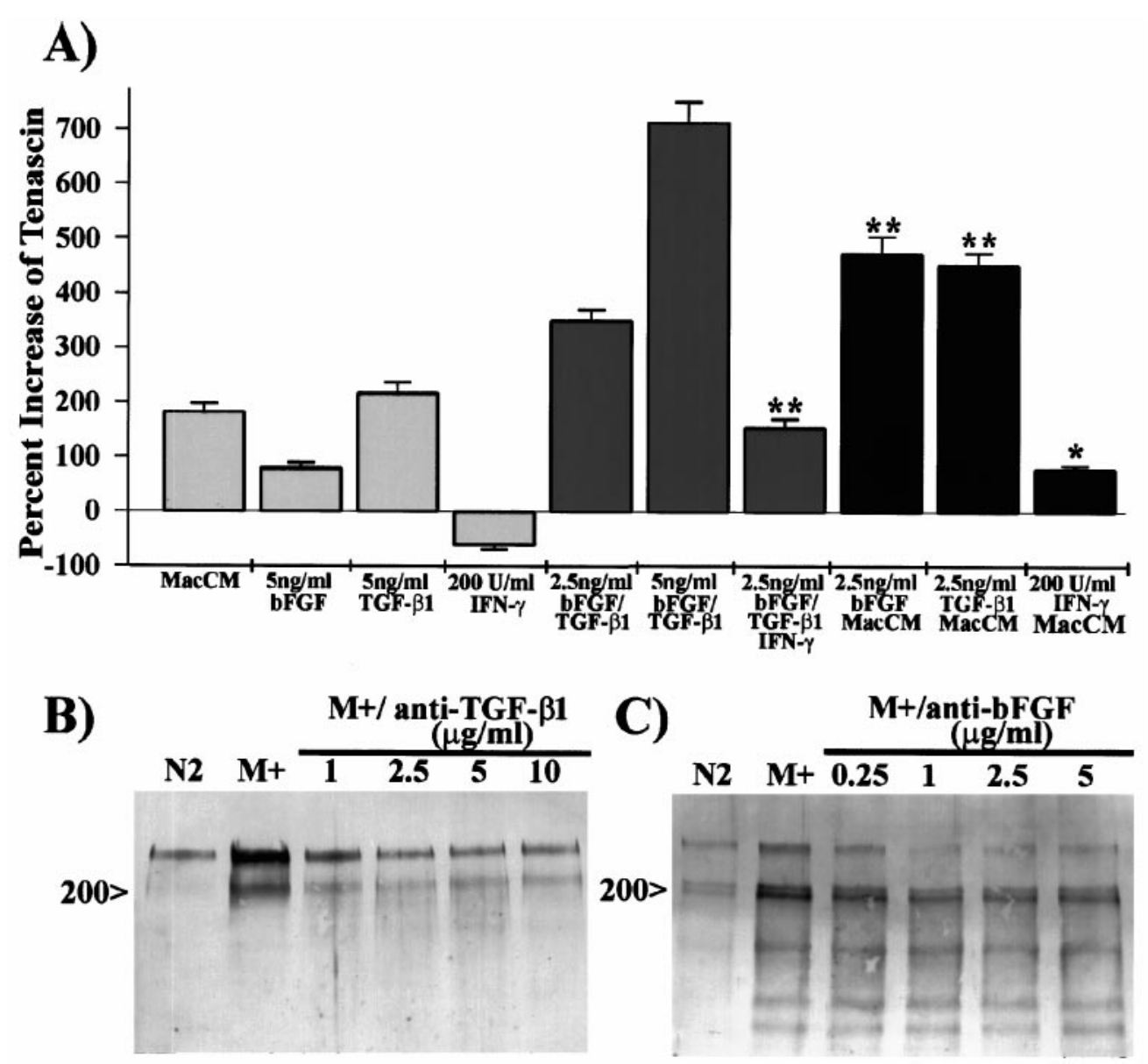

Figure 5. Tenascin expression in the presence of activated macrophage-CM is induced by a synergistic effect between TGF- $\beta 1$ and bFGF. $A$, To examine the possibility that either TGF- $\beta 1$ or bFGF could potentiate the effect of activated macrophage-conditioned medium (MacCM), we determined the relative amount of tenascin by ELISA of supernatants of astrocytes grown in Sato's alone, $40 \%$ MacCM, TGF- $\beta 1$, bFGF, TGF- $\beta 1$ and bFGF, or $40 \%$ MacCM containing $2.5 \mathrm{ng} / \mathrm{ml}$ TGF- $\beta 1$ or bFGF. Astrocytes grown in the presence of $5 \mathrm{ng} / \mathrm{ml} \mathrm{bFGF,} 5 \mathrm{ng} / \mathrm{ml} \mathrm{TGF}$ $\beta 1$, and 2.5 or $5 \mathrm{ng} / \mathrm{ml} \mathrm{bFGF}$ and TGF- $\beta 1$ produce 0.4 -fold, 1.2-fold, 2.0fold, and 3.8-fold, respectively, the amount of tenascin as do those grown in $40 \%$ MacCM. The addition of 2.5 $\mathrm{ng} / \mathrm{ml}$ bFGF or TGF- $\beta 1$ to $40 \%$ MacCM, however, caused a 2.5 -fold increase in tenascin compared with the addition of MacCM alone. This potentiation is greater than an additive effect of the individual factors and suggests that both bFGF and TGF- $\beta 1$ are present in these culture conditions. The addition of $200 \mathrm{U} / \mathrm{ml}$ IFN- $\gamma$ to Sato's $\mathrm{N} 2$ medium alone, $2.5 \mathrm{ng} / \mathrm{ml} \mathrm{bFGF}$ and TGF- $\beta 1$, or $40 \%$ MacCM reduced tenascin expression by 40,55 , and $55 \%$, respectively, compared with identical treatments in the absence of IFN- $\gamma . B$, $C$, To further examine the contribution of either TGF- $\beta 1$ or bFGF, we pretreated activated macrophage-CM $(M+)$ with antibodies that neutralize the activity of TGF- $\beta 1(B)$ or bFGF $(C)$ before addition of the media to astrocytes. Immunoblot analysis of tenascin in astrocyte supernatants shows a distinct reduction in the expression of tenascin when $M+$ was pretreated with either anti-TGF- $\beta 1$ or anti-bFGF. Error bars represent the SD; ${ }^{*} p<0.01 ; * * p<0.001$.

equally potentiate tenascin production, indicating the endogenous presence of both bFGF and TGF- $\beta 1$ in astrocyte cultures treated with macrophage-CM.

Interferon- $\gamma$ is expressed by $\mathrm{T}$ cells in many forms of injury, such as multiple sclerosis, experimental allergic encephalomyelitis, and almost any injury in which $\mathrm{T}$ cells enter the brain (Yong et al., 1991). Interferon- $\gamma$ is an important inflammatory cytokine that has been shown to activate macrophages and microglia and to induce astrocyte reactivity (Lotan and Schwartz, 1994; Gehrmann et al., 1995). In earlier experiments, we observed that IFN- $\gamma$ reduced tenascin expression by astrocytes grown in serumfree medium. This response is also dose-dependent and shows a maximal repression of astrocytic tenascin at a concentration between 100 and $200 \mathrm{U} / \mathrm{ml}$ IFN- $\gamma$ (data not shown). In combinatorial experiments, IFN- $\gamma$ consistently reduced tenascin expression by $55-60 \%$ compared with matched culture conditions grown in the absence of IFN- $\gamma$ (Fig. $5 A$ ), indicating that this cytokine represses the expression of tenascin by astrocytes grown in the presence of growth factors.

To directly determine whether TGF- $\beta 1$ and bFGF functioned synergistically to upregulate tenascin expression, we treated astrocytes with $40 \%$ activated macrophage-CM alone or after pretreatment with antibodies that neutralized the activity of either TGF- $\beta 1$ or bFGF. Western blot analysis of samples pretreated with anti-TGF- $\beta 1$ shows a prominent reduction in the expression of tenascin when compared with that caused by macrophage-CM alone (Fig. $5 B$ ). The addition of antibody at $\geq 2.5 \mu \mathrm{g} / \mathrm{ml}$ reduced the amount of tenascin, particularly the $200 \mathrm{kDa}$ doublet, to the amount reminiscent of astrocytes treated with Sato's N2 medium alone. Pretreatment with anti-bFGF showed a reduction in tenascin expression similar to that observed with anti-TGF- $\beta 1$; however, there was a persistence in the expression of the $200 \mathrm{kDa}$ doublet and a substantial reduction in the $250 \mathrm{kDa}$ band (Fig. $5 \mathrm{C}$ ). The prominence of the 200 and $250 \mathrm{kDa}$ tenascin bands, however, was variable when astrocytes were grown in the presence of either macrophage- or microglial-CM. This variability may be caused by differences in the amount of activated TGF- $\beta 1$ in macrophage- or microglial-CM or in the release of bFGF by astrocytes. Astrocytes grown in the presence of macrophage-CM alone or pretreated with different concentrations of normal goat serum showed no change in the relative expression of tenascin (data not shown). These neutralization experiments demonstrate the synergistic action of TGF- $\beta 1$ and bFGF for the induction of tenascin by macrophage-CM. These data also reinforce the differential expression of tenascin isoforms by these two growth factors.

\section{Injury to the postnatal or adult brain induces a concomitant increase in tenascin, TGF- $\beta 1$, and bFGF}

Our in vitro data show that activated macrophage- and microglialconditioned media induces the upregulation of tenascin by astrocytes. This upregulation is, most likely, mediated by a combined expression and release of TGF- $\beta 1$ and bFGF from microglia and 


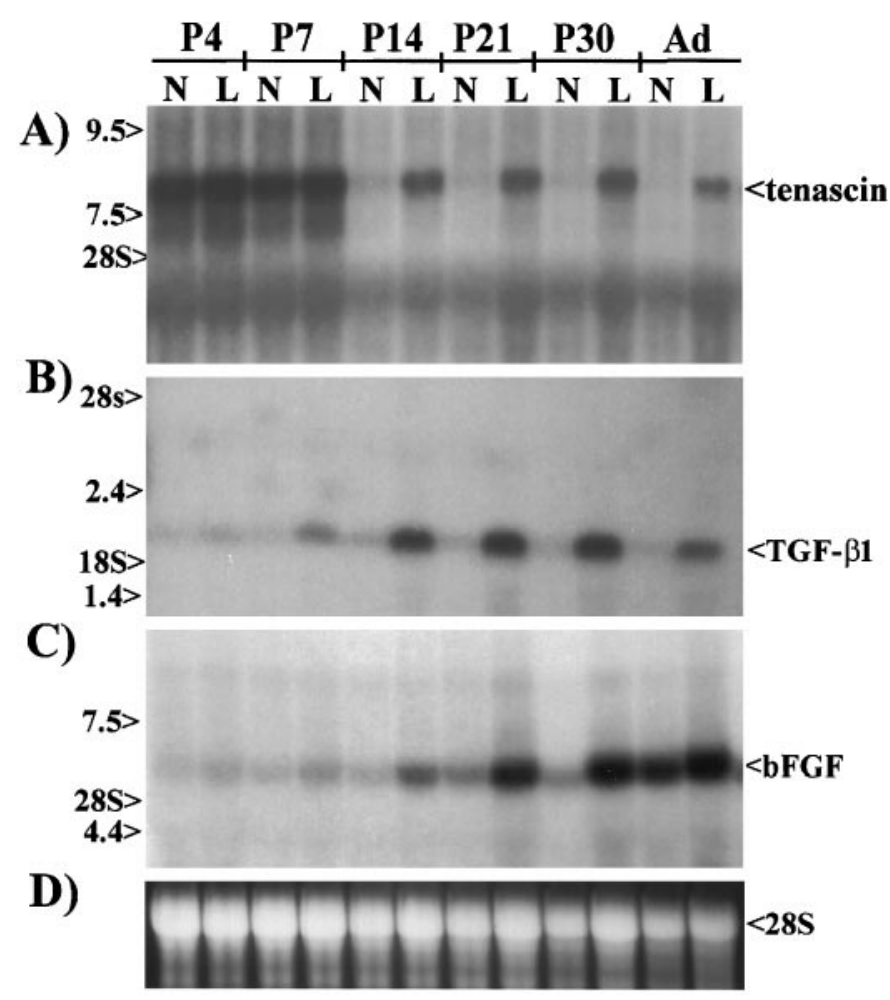

Figure 6. Increased tenascin expression after injury to the late postnatal and adult brain correlates with a concomitant increase in the expression of TGF- $\beta 1$ and bFGF. To examine the possibility that tenascin expression after injury in vivo is upregulated by the production of TGF- $\beta 1$ and bFGF, we examined mRNA from normal $(N)$ and lesioned $(L)$ 4-, 7-, 14-, 21-, and 30-d-old and adult rat brains by Northern blot analysis. $A$, Northern blots probed for tenascin show high expression in both normal and lesioned neonatal brains; however, in late postnatal ( $\geq \mathrm{P} 14)$ and adult rats, detectable amounts of tenascin mRNA were only observed in the lesioned brains. $B$, Northern analyses for TGF- $\beta 1$ mRNA show very little expression in the neonates or in normal postnatal and adult brains; however, TGF- $\beta 1$ mRNA was easily detectable in lesioned postnatal and adult brains. $C$, Northern blots probed with antisense bFGF cRNA show injury-induced increases similar to those observed for TGF- $\beta 1$. $D$, Ethidium bromide staining of 28S ribosomal RNA from the gel of the blot in $A$ shows equal loading of RNA. Gels were loaded with $10 \mu \mathrm{g} / \mathrm{lane}$ of total RNA for tenascin blots and $25 \mu \mathrm{g} /$ lane of total RNA for TGF- $\beta 1$ and bFGF blots.

astrocytes, respectively. To determine whether a similar mechanism for tenascin upregulation occurs in vivo, we examined lesioned brains at various ages from newborns to adults by Northern blot analysis for the expression of tenascin, TGF- $\beta 1$, and bFGF (Fig. 6). These ages were selected because injury-induced increases in tenascin expression do not occur within the first week of birth (McKeon et al., 1991), although tenascin is expressed at the boundary of cortical barrels (Steindler et al., 1989). Northern blots probed for tenascin showed an $8.0 \mathrm{~kb}$ transcript present in both normal and injured 4- and 7-d-old rat pups (Fig. 6A). In animals $14 \mathrm{~d}$ of age and older, there was no detectable amount of tenascin in normal brains; however, after injury, tenascin expression dramatically increased (Fig. $6 A$ ). The high levels of tenascin mRNA observed in the normal brains of neonates and the subsequent decline to $14 \mathrm{~d}$ of age and older are consistent with previous studies (Steindler et al., 1989; Mitrovic et al., 1994). Similar blots probed for TGF- $\beta 1$ transcripts showed negligible expression of TGF- $\beta 1$ in normal brains at all ages (Fig. $6 B$ ). After injury, a small increase in TGF- $\beta 1$ was first detected in rat pups
$7 \mathrm{~d}$ of age. In rats $14 \mathrm{~d}$ of age or older, there was a substantial increase in TGF- $\beta 1$ expression after brain injury. Northern blots probed with bFGF antisense cRNA showed an expression pattern similar to that observed for TGF- $\beta 1$ with increased expression of bFGF after injury. The increase after injury to adults is not as dramatic as that observed in pups $14-30 \mathrm{~d}$ old because of the higher expression of bFGF mRNA in noninjured adults (Fig. 6C). These data correlate with our in vitro observations and strongly indicate that the coexpression and release of TGF- $\beta 1$ and bFGF after injury induce the upregulation of tenascin observed around CNS wounds.

\section{DISCUSSION}

Within the normal adult CNS, microglia are believed to be quiescent or in a nonactivated state in which they most likely perform a housekeeping role. After injury, microglia become activated, and with disruption of the vasculature, blood-borne monocytes migrate into the wound cavity, where they also become activated. After activation, these macrophages secrete numerous cytokines (IL-1, IL-6, IFN- $\gamma$, TNF- $\alpha$, etc.), growth factors (e.g., TGF- $\beta 1$ ), and phagocytosed tissue debris. The activation of microglia and the subsequent release of cytokines may then induce reactive gliosis (Giulian et al., 1994). Previously, it has been shown that IL-1, IL-6, and TGF- $\beta 1$ contribute to reactive gliosis by stimulating astrocyte proliferation or hypertrophy or by increasing GFAP expression (Giulian et al., 1988). In this study we demonstrated that TGF- $\beta 1$ released from activated macrophages and microglia also has a profound effect on increasing the extracellular matrix molecule tenascin. In addition, the release of TGF- $\beta 1$ from activated microglia might also induce the expression of fibronectin (Pasinetti et al., 1993) and laminin (Logan et al., 1994) by astrocytes around the lesion site. The expression of these extracellular matrix molecules could dramatically effect the wound-healing process by promoting cell migration, neovascularization, and the formation of the glial scar observed after penetrating injuries.

Of the growth factors and cytokines examined, only TGF- $\beta 1$ and bFGF induced the upregulation of tenascin, in which the maximum induction by TGF- $\beta 1$ was threefold greater than that of bFGF in serum-free conditions. Previous studies have shown that TGF- $\beta 1$, bFGF, and serum can upregulate the expression of tenascin by fibroblasts (Pearson et al., 1988; Tucker et al., 1993) and that bFGF can induce tenascin expression in astrocytes (Meiners et al., 1993). In these studies, the greatest increases in tenascin expression by bFGF were observed in the presence of serum. Serum is known to have a high concentration of TGF- $\beta 1$ from the disruption of platelets (Assoian et al., 1983), and this TGF- $\beta 1$ most likely potentiated the expression of tenascin. The tenascin gene itself contains multiple promoter elements that can interact with transcriptional activators or repressors such as Krox and nuclear factor 1 , which can, in turn, be regulated by either TGF- $\beta 1$ or bFGF (Copertino et al., 1997). One surprising finding in this study was the downregulation of tenascin expression when astrocytes were grown in the presence of IFN- $\gamma$. In all experiments, the addition of IFN- $\gamma$ significantly reduced $(\sim 50 \%)$ the expression of tenascin when astrocytes were grown in serum-free medium alone or with either activated macrophage-CM or a combination of TGF- $\beta 1$ and bFGF. This further demonstrates differential regulation of tenascin in the presence of specific cytokines.

Examination for the presence of these growth factors by Western blot analysis and ELISA indicates that TGF- $\beta 1$ was present in 
activated macrophage- and microglial-CM but not in astrocyteCM. Other studies have also demonstrated the expression of TGF- $\beta 1$ by activated macrophages and microglia both in vitro (Assoian et al., 1987) and in vivo (Lindholm et al., 1992; Logan et al., 1992; Pasinetti et al., 1993). After CNS injury, induction of TGF- $\beta 1$ is rapid, occurring within the first day, peaking within 2-3 d, and decreasing 7-14 d after injury (Logan et al., 1992). TGF- $\beta 1$ is released from cells as a nonactive latent form with an apparent molecular weight of $210 \mathrm{kDa}$ (Miyazono et al., 1988) and activated by either transient acidification (Wakefield et al., 1987), proteolytic cleavage of latent associated peptide (Lyons et al., 1988), removal of carbohydrate from TGF- $\beta 1$ (Miyazono and Heldin, 1989), or complex generation in the presence of thrombospondin (Schultz-Cherry and Murphy-Ullrich, 1993). Western blot analysis of TGF- $\beta 1$ released from activated macrophages and microglia shows that most of the TGF- $\beta 1$ migrated at $25 \mathrm{kDa}$, which is representative of the active dimer. A low abundance of inactive preprocessed TGF- $\beta 1$ was observed as bands that migrated at apparent molecular weights of 40 and $31 \mathrm{kDa}$, with the $40 \mathrm{kDa}$ isoform being the glycosylated form that is associated with the latent complex (Miyazono and Heldin, 1989). The high abundance of active TGF- $\beta 1$ in these supernatants may be attributable to the release of proteases, such as plasminogen activator, by activated macrophages and microglia (Nakajima et al., 1992; Gottschall et al., 1995).

Immunoblot analysis of supernatants and cells indicated that astrocytes were the only source containing detectable concentrations of bFGF. Although we could not detect bFGF within astrocyte supernatants, it was relatively abundant within the cytosol. This behavior of bFGF has also been observed in many other cells (Moscatelli et al., 1986; Schweigerer et al., 1987; Rogelj et al., 1989), but the physiological mechanism by which bFGF is released from cells is unknown because it lacks a signal sequence for secretion (Abraham et al., 1986). bFGF can be released from cells either by perturbation of the cell membrane, sublethal injury, and cell death (McNeil et al., 1989; Ku and D'Amore, 1995), or by an undefined endoplasmic reticulum-Golgi independent mechanism other than cell injury (Mignatti et al., 1992). These mechanisms may explain the low levels of tenascin expression when astrocytes were grown in the absence of growth factors. The addition of either macrophage- or microglial-CM, but not recombinant TGF- $\beta 1$, could have augmented the release of bFGF by any of the above mechanisms. The more probable mechanism for release of bFGF might be attributable to lethal or sublethal cellular injury because activated macrophages and microglia are known to secrete several factors that induce cell death, such as $\mathrm{TNF}-\alpha$, and free radicals. In addition, when the concentration of macrophage-CM exceeded $50 \%$, signs of cell death were observed, and at concentrations higher than $70 \%$, the monolayer detached from the dish. Although the vast majority of cells were viable after replating, significant numbers of dead cells were still apparent. In the presence of activated macrophage-CM, bFGF was most likely released from astrocytes because the addition of bFGF neutralizing antibodies could reduce, whereas the addition of TGF- $\beta 1$ could potentiate, tenascin production.

Although TGF- $\beta 1$ was detected in activated macrophage and microglial supernatants, the concentration of this molecule was less than half that expected when compared with an equivalent increase in tenascin expression induced by purified recombinant TGF- $\beta 1$. This led us to speculate that the effect of TGF- $\beta 1$ on tenascin expression might be potentiated by another factor. In combinatorial experiments, examination of tenascin expression by astrocytes grown in the presence of two or more cytokines showed a strong potentiation of TGF- $\beta 1$ by bFGF. Using purified cytokines, we observed this effect to be robust, with the relative increase in tenascin production at the $\mathrm{ED}_{50}$ almost doubled and at a fourfold lower concentration of TGF- $\beta 1$ when an equivalent amount of bFGF was added to the TGF- $\beta 1$. This effect was also apparent when either TGF- $\beta 1$ or bFGF at $2.5 \mathrm{ng} / \mathrm{ml}$ was added to activated macrophage-conditioned medium and reflects the presence of both TGF- $\beta 1$ and bFGF, as determined using neutralizing antibodies. This synergistic effect has also been observed for tenascin production from fibroblasts (Tucker et al., 1993). Under such circumstances, the production of these growth factors after a penetrating injury would not only effect matrix production by astrocytes but also by meningeal fibroblasts, contributing even further to the formation of the glial scar. In agreement with these observations, Logan et al. (1994) demonstrated that exogenous application of TGF- $\beta 1$ to lesioned brains exacerbated glial scar formation, whereas administration of antibodies that neutralize TGF- $\beta 1$ attenuated it.

The prospects that bFGF and TGF- $\beta 1$ induce an upregulation in tenascin expression were further substantiated by their correlated expression after injury to the CNS. Brain injury in rats $14 \mathrm{~d}$ of age or older showed a dramatic increase in tenascin, TGF- $\beta 1$, and bFGF expression. This postnatal injury- induced expression also correlated with a critical period (between 7 and $14 \mathrm{~d}$ of age) in which glial scars begin to form and the potential for callosal axon regeneration ends (Smith et al., 1986). In neonates, tenascin, but not TGF- $\beta 1$ or bFGF, was expressed in both nonlesioned and lesioned brains. During this neonatal period, tenascin is expressed at the boundary of individual cortical barrels (Steindler et al., 1989). This indicates that TGF- $\beta 1$ and bFGF induce the expression of tenascin after brain injury in postcritical period rats, but they do not regulate the developmental expression of tenascin.

The exact role tenascin plays in CNS wound healing and regeneration remains undetermined. Tenascin does, however, seem to display contrary multifunctional properties, in which it can support cell binding but inhibits cell spreading (ChiquetEhrismann et al., 1988; Lochter et al., 1991). It can also support axon growth of some neuronal populations when bound to a substrate under nonchoice paradigms but reduces neurite outgrowth over substrates of fibronectin, laminin, and tenascin when soluble (Lochter et al., 1991). In these experiments, we only identified tenascin as a soluble component released by astrocytes into the tissue culture medium and did not observe increased cell-surface binding of tenascin by either Western blot analysis or immunofluorescence. This seems consistent with the diffuse extracellular staining pattern for tenascin observed in vivo, in which very little cell-surface staining is apparent. Tenascin may, however, interact with other extracellular matrix molecules, such as chondroitin sulfate proteoglycans (Chiquet and Fambrough, 1984), also upregulated near the wound site after injury. Tenascin expression is very abundant around the wound site, with a sharp lateral demarcation between the injured and intact brain (Laywell et al., 1992). In tissue culture experiments such abrupt boundaries between tenascin and other substrates resulted in growth cone turning at the border and exclusion from the area of bound tenascin (Faissner and Kruse, 1990; Perez and Halfter, 1993; Taylor et al., 1993). Culture explants of wounded mouse neostriatum also illustrate this dichotomy of function for tenascin, in which perturbation with antibodies to tenascin reduced attachment of dopaminergic neurons but increased neurite out- 
growth from those that did attach (Gates et al., 1996). Thus, tenascin may play an important role in restricting axon growth into the wound cavity during closure, possibly preventing the establishment of anomalous connections or further neuronal damage (for review, see Brodkey et al., 1993).

\section{REFERENCES}

Abraham JA, Mergia A, Whang JI, Tumolo A, Friedman J, Hjerrild KA, Gospodarowicz D, Fiddes JC (1986) Nucleotide sequence of a bovine clone encoding the angiogenic protein, basic fibroblast growth factor. Science 233:545-548.

Assoian RK, Komoriya A, Meyers CA, Miller DM, Sporn MB (1983) Transforming growth factor-B in human platelets. J Biol Chem 258:7155-7160.

Assoian RK, Fleurdelys BE, Stevenson HC, Miller PJ, Madtes DK, Raines EW, Ross R, Sporn MB (1987) Expression and secretion of type B transforming growth factor by activated human macrophages. Proc Natl Acad Sci USA 84:6020-6024.

Baghdassarian D, Toru-Delbauue D, Gavaret JM, Pierre M (1993) Effects of transforming growth factor-beta 1 on the extracellular matrix and cytoskeleton of cultured astrocytes. Glia 7:193-202.

Brodkey JA, Gates MA, Laywell ED, Steindler DA (1993) The complex nature of interactive neuroregeneration-related molecules. Exp Neurol 123:251-270.

Chiquet M, Fambrough DM (1984) Chick myotendinous antigen. II. A novel extracellular glycoprotein complex consisting of large disulfidelinked subunits. J Cell Biol 98:1937-1946.

Chiquet-Ehrismann R, Kalla P, Pearson CA, Beck K, Chiquet M (1988) Tenascin interferes with fibronectin action. Cell 53:383-390.

Chiquet-Ehrismann R, Matsuoka Y, Hofer U, Spring J, Bernasconi C, Chiquet M (1991) Tenascin variants: differential binding to fibronectin and distinct distribution in cell cultures and tissues. Cell Regul 2:927-938.

Copertino DW, Edelman GM, Jones FS (1997) Multiple promoter elements differentially regulate the expression of the mouse tenascin gene. Proc Natl Acad Sci USA 93:1846-1851.

Danielpour D, Kim KY, Dart LL, Watanabe S, Roberts AB, Sporn MB (1990) Evidence for differential regulation of TGF $\beta 1$ and TGF $\beta 2$ expression in vivo by sandwich enzyme-linked immunosorbent assays. Ann NY Acad Sci 593:300-302.

Faissner A, Kruse J (1990) J1/tenascin is a repulsive substrate for central nervous system neurons. Neuron 5:627-637.

Faissner A, Kruse J, Kuhn K, Schachner M (1990) Binding of the J1 adhesion molecules to extracellular matrix constituents. J Neurochem 54:1004-1015.

Gates MA, Fillmore H, Steindler DA (1996) Chondroitin sulfate proteoglycan and tenascin in the wounded adult mouse neostriatum in vitro: dopamine neuron attachment and process outgrowth. J Neurosci 16:8005-8018.

Gehrmann J, Matsumoto Y, Kreutzberg GW (1995) Microglia: intrinsic immuneffector cell of the brain. Brain Res Rev 20:269-287.

Giulian D, Baker TJ (1986) Characterization of ameboid microglia isolated from developing mammalian brain. J Neurosci 6:2163-2178.

Giulian D, Woodward J, Young DG, Krebs JFE (1988) Interleukin-1 injected into the mammalian brain stimulates astrogliosis and neovascularization. J Neurosci 8:2485-2490.

Giulian D, Li J, Li X, George J, Rutecki PA (1994) The impact of microglia-derived cytokines upon gliosis in the CNS. Dev Neurosci 16:128-136.

Gottschall PE, Yu X, Bing B (1995) Increased production of gelatinase B (matrix metalloproteinase-9) and interleukin-6 by activated rat microglia in culture. J Neurosci Res 42:335-342.

Ku P, D'Amore PA (1995) Regulation of basic fibroblast growth factor (bFGF) gene and protein expression following its release from sublethally injured endothelial cells. J Cell Biochem 58:328-343.

Laywell ED, Dorries U, Bartsch U, Faissner A, Schachner M, Steindler DA (1992) Enhanced expression of the developmentally regulated extracellular matrix molecule tenascin following adult brain injury. Proc Natl Acad Sci USA 89:2634-2638.

Lightner VA, Erickson HP (1990) Binding of hexabrachion (tenascin) to the extracellular matrix and substratum and its effect on cell adhesion. J Cell Sci 95:263-277.
Lindholm D, Castren E, Kiefer R, Zafra F, Thoenen H (1992) Transforming growth factor-B1 in the rat brain: increase after injury and inhibition of astrocyte proliferation. J Cell Biol 117:395-400.

Lindsay RM, Barber PC, Sherwood MRC, Zimmer J, Raisman G (1982) Astrocyte cultures from adult rat brain. Derivation, characterization and neurotrophic properties of pure astroglial cells from the corpus callosum. Brain Res 243:329-343.

Lochter A, Vaughan L, Kaplony A, Prochiantz A, Schachner M, Faissner A (1991) J1/tenascin in substrate-bound and soluble form displays contrary effects on neurite outgrowth. J Cell Biol 113:1159-1171.

Logan A, Frautschy SA, Gonzalez A, Sporn MB, Baird A (1992) Enhanced expression of transforming growth factor B1 in the rat brain after a localized cerebral injury. Brain Res 587:216-225.

Logan A, Berry M, Gonzalez AM, Frautschy SA, Sporn MB, Baird A (1994) Effects of transforming growth factor B1 on scar production in the injured central nervous system of the rat. Eur J Neurosci 6:355-363.

Lotan M, Schwartz M (1994) Cross talk between the immune system and the nervous system in response to injury: implications for regeneration. FASEB J 8:1026-1033.

Lotz MM, Burdsal CA, Erickson HP, McClay DR (1989) Cell adhesion to fibronectin and tenascin: quantitative measurements of initial binding and subsequent strengthening response. J Cell Biol 1989:1795-1805.

Lyons RM, Keski-Oja J, Moses HL (1988) Proteolytic activation of latent transforming growth factor-B from fibroblast-conditioned medium. J Cell Biol 106:1659-1665.

McKeon RJ, Schreiber RC, Rudge JS, Silver J (1991) Reduction of neurite outgrowth in a model of glial scarring following CNS injury is correlated with expression of inhibitory molecules on reactive astrocytes. J Neurosci 11:3398-3411.

McNeil PL, Muthukrishnan L, Warder E, D’Amore PA (1989) Growth factors are released by mechanically wounded endothelial cells. J Cell Biol 109:811-822.

Meiners S, Marone M, Rittenhouse JL, Geller HM (1993) Regulation of astrocytic tenascin by basic fibroblast growth factor. Dev Biol 160:480-493.

Mignatti P, Morimoto T, Rifkin DB (1992) Basic fibroblast growth factor, a protein devoid of secretory signal sequence, is released by cells via a pathway independent of the endoplasmic reticulum-Golgi complex. J Cell Physiol 151:81-93.

Mitrovic N, Dorries U, Schachner M (1994) Expression of the extracellular matrix glycoprotein tenascin in the somatosensory cortex of the mouse during postnatal development: an immunocytochemical and in situ hybridization analysis. J Neurocytol 23:364-378.

Miyazono K, Heldin C (1989) Role of carbohydrate structures in TGF-B1 latency. Nature 338:158-160.

Miyazono K, Hellman U, Wernstedt C, Heldin C (1988) Latent high molecular weight complex of transforming growth factor B1. J Biol Chem 263:6407-6415.

Moscatelli D, Presta M, Joseph-Silverstein J, Rifkin DB (1986) Both normal and tumor cells produce basic fibroblast growth factor. J Cell Physiol 129:273-276.

Nakajima K, Tsuzaki N, Shimojo M, Hamanoue M, Kohsaka S (1992) Microglia isolated from rat brain secrete a urokinase-type plasminogen activator. Brain Res 577:285-292.

Pasinetti GM, Nichols NR, Tocco G, Morgan T, Laping N, Finch CE (1993) Transforming growth factor B1 and fibronectin messenger RNA in rat brain: responses to injury and cell-type localization. Neuroscience 54:893-907.

Pearson CA, Pearson D, Shibahara S, Hofsteenge J (1988) Tenascin: cDNA cloning and induction by TGF- $\beta$. EMBO J 7:2977-2981.

Perez RG, Halfter W (1993) Tenascin in the developing chick visual system: distribution and potential role as a modulator of retinal axon growth. Dev Biol 156:278-292.

Riou JF, Shi DL, Chiquet M, Boucaut JC (1990) Tenascin inhibits mesodermal cell migration during amphibian gastrulation. Dev Biol 137:305-317.

Rogelj S, Klagsbrun M, Atzmon R, Kurokawa M, Haimovitz A, Fuks Z, Vlodavsky I (1989) Basic fibroblast growth factor is an extracellular matrix component required for supporting the proliferation of vascular endothelial cells and the differentiation of PC12 cells. J Cell Biol 109:823-831.

Sanguedolce MV, Capo C, Bongrand P, Mege JL (1992) Zymosanstimulated tumor necrosis factor-alpha production by human monocytes. Down-modulation by phorbol ester. J Immunol 148:2229-2236. 
Schultz-Cherry S, Murphy-Ullrich JE (1993) Thrombospondin causes activation of latent transforming growth factor-B secreted by endothelial cells by a novel mechanism. J Cell Biol 122:923-932.

Schweigerer L, Neufeld G, Friedman J, Abraham JA, Fiddes JC, Gospodarowicz D (1987) Capillary endothelial cells express basic fibroblast growth factor, a mitogen that promotes their own growth. Nature 325:257.

Smith GM, Miller RH, Silver J (1986) Changing role of forebrain astrocytes during development, regenerative failure, and induced regeneration upon transplantation. J Comp Neurol 251:23-43.

Smith GM, Rutishauser U, Silver J, Miller RH (1990) Maturation of astrocytes in vitro alters the extent and molecular basis of neurite outgrowth. Dev Biol 138:377-390.

Steindler DA, Cooper NGF, Faissner A, Schachner M (1989) Boundaries defined by adhesion molecules during development of the cerebral cortex: the $\mathrm{J} 1 /$ tenascin glycoprotein in the mouse somatosensory cortical barrel field. Dev Biol 131:243-260.

Sriramarao P, Mendler M, Bourdon MA (1993) Endothelial cell attachment and spreading on human tenascin is mediated by $\alpha 2 \beta 1$ and $\alpha \mathrm{v} \beta 3$ integrins. J Cell Sci 105:1001-1012.
Taylor J, Pesheva P, Schachner M (1993) Influence of janusin and tenascin on growth cone behavior in vitro. J Neurosci Res 35:347-362.

Tucker RP, Hammarback JA, Jenrath DA, Mackie EJ, Xu Y (1993) Tenascin expression in the mouse: in situ localization and induction in vitro by bFGF. J Cell Sci 104:69-76.

Wakefield LM, Smith DM, Masui T, Harris CC, Sporn MB (1987) Distribution and modulation of the cellular receptor for transforming growth factor-beta. J Cell Biol 105:965.

Wyss-Coray T, Feng L, Masliah E, Ruppe MD, Lee HS, Toggas SM, Rockenstein EM, Mucke L (1995) Increased central nervous system production of extracellular matrix components and development of hydrocephalus in transgenic mice overexpressing transforming growth factor-B1. Am J Pathol 147:53-67.

Yong VW, Moumdjian R, Yong FP, Ruijs TC, Freedman MS, Cashman N, Antel JP (1991) Gamma-interferon promotes proliferation of adult human astrocytes in vitro and reactive gliosis in the adult mouse brain in vivo. Proc Natl Acad Sci USA 88:7016-7020.

Xie WQ, Rothblum LI (1991) Rapid, small-scale RNA isolation from tissue culture cells. Biotechniques 11:325-327. 